\title{
c. \\ Comparative Metabolite Profiling of Traditional and Commercial Vinegars in Korea
}

\author{
Minhye Shin ${ }^{1,+} \mathbb{D}^{D}$, Jeong-Won Kim ${ }^{2,+}$, Bonbin $\mathrm{Gu}^{2}$, Sooah Kim ${ }^{3}$, Hojin Kim ${ }^{4}$, Won-Chan Kim ${ }^{5}$, \\ Mee-Ryung Lee ${ }^{6, *}$ and Soo-Rin Kim ${ }^{2, *(D)}$
}

1 Department of Microbiology, College of Medicine, Inha University, Incheon 22212, Korea; alsgp01@gmail.com

2 School of Food Science and Biotechnology, Kyungpook National University, Daegu 41566, Korea; jungwon1103@naver.com (J.-W.K.); ant369369@naver.com (B.G.)

3 Department of Environment Science \& Biotechnology, Jeonju University, Jeonju 55069, Korea; skim366@jj.ac.kr

4 Experimental Research Institute, National Agricultural Products Quality Management Service, Gimcheon-si 39660, Korea; rex7878@korea.kr

5 School of Applied Biosciences, Kyungpook National University, Daegu 41566, Korea; kwc@knu.ac.kr

6 Department of Food and Nutrition, Daegu University, Gyeongsan 38453, Korea

* Correspondence: mrlee@daegu.ac.kr (M.-R.L.); soorinkim@knu.ac.kr (S.-R.K.)

+ Two authors contributed equally to this work.

check for updates

Citation: Shin, M.; Kim, J.-W.; Gu, B.; Kim, S.; Kim, H.; Kim, W.-C.; Lee, M.-R.; Kim, S.-R. Comparative Metabolite Profiling of Traditional and Commercial Vinegars in Korea. Metabolites 2021, 11, 478. https:// doi.org/10.3390/metabo11080478

Academic Editor: Farhana R. Pinu

Received: 15 June 2021

Accepted: 23 July 2021

Published: 24 July 2021

Publisher's Note: MDPI stays neutral with regard to jurisdictional claims in published maps and institutional affiliations.

Copyright: (c) 2021 by the authors. Licensee MDPI, Basel, Switzerland. This article is an open access article distributed under the terms and conditions of the Creative Commons Attribution (CC BY) license (https:// creativecommons.org/licenses/by/ $4.0 /)$.

\begin{abstract}
Vinegar, composed of various organic acids, amino acids, and volatile compounds, has been newly recognized as a functional food with health benefits. Vinegar is produced through alcoholic fermentation of various raw materials followed by acetic acid fermentation, and detailed processes greatly vary between different vinegar products. This study performed metabolite profiling of various vinegar products using gas chromatography-mass spectrometry to identify metabolites that are specific to vinegar production processes. In particular, seven traditional vinegars that underwent spontaneous and slow alcoholic and acetic acid fermentations were compared to four commercial vinegars that were produced through fast acetic acid fermentation using distilled ethanol. A total of 102 volatile and 78 nonvolatile compounds were detected, and the principal component analysis of metabolites clearly distinguished between the traditional and commercial vinegars. Ten metabolites were identified as specific or significantly different compounds depending on vinegar production processes, most of which had originated from complex microbial metabolism during traditional vinegar fermentation. These process-specific compounds of vinegars may serve as potential biomarkers for fermentation process controls as well as authenticity and quality evaluation.
\end{abstract}

Keywords: GC/MS; metabolomics; vinegar; lactic acid; propanoic acid; erythritol; 2,3-butanediol

\section{Introduction}

Vinegar is currently recognized as a functional food due to its potential health benefits, including antioxidant [1], antidiabetic [2], cholesterol-lowering [3], weight-reducing [4], and immune-boosting [5] activities. The most representative vinegars include balsamic, apple, and brown rice vinegars, and their authentic traditional products are preferred by consumers [6]. Recent metabolomic analysis of traditional vinegars suggested that vinegar fermentation processes alter vinegar compounds and possibly their functional properties [7-12].

Traditional vinegar is produced by two consecutive fermentation processes: alcoholic fermentation and acetic acid fermentation. During alcoholic fermentation, yeast (Saccharomyces cerevisiae) converts fermentable sugars in the raw materials into ethanol. Then, acetic acid bacteria are introduced and ethanol is oxidized into acetic acid [13]. Traditional vinegar fermentation is often performed spontaneously by indigenous microorganisms, leading to a slow and complex fermentation process [14]. On the other hand, most of the commercially available vinegars are produced by fast acetic acid fermentation of distilled ethanol by a starter culture (the mother of vinegar) [15]. 
Vinegar is composed of various organic acids, amino acids, and volatile compounds that originate from raw materials and are produced by microbial fermentation. Different metabolite profiles of vinegar contribute to different flavors and functional properties [16,17]. Previously, non-volatile metabolites of Korean traditional vinegars were compared to those of commercial vinegars, and the presence and levels of some sugars and acids were identified as being significantly different between the two groups [18]. However, the unique volatile metabolites of Korean traditional vinegars have rarely been investigated.

In this study, volatile and non-volatile metabolite profiling of traditional and commercial vinegars in Korea was performed using gas chromatography-mass spectrometry. Specifically, all seven traditional vinegars certified so far in Korea (the Ministry of Agriculture, Food and Rural Affairs, Korea) were used for the comparative metabolite profiling. Additionally, vinegars made from various ingredients were included in both groups (traditional vs. commercial) to focus on different fermentation processes rather than raw materials. Through this comparative metabolite profiling, the purpose of this study is to identify vinegar compounds specific to traditional fermentation processes.

\section{Results and Discussion}

\subsection{Metabolomic Differences between Traditional Vinegars and Commercial Vinegars}

From the GC/MS analysis of seven traditional vinegar (TV) and four commercial vinegar (CV) samples (Table 1), 102 volatile and 78 nonvolatile compounds were identified. The partial least square discriminant analysis (PLS-DA) of the volatile and nonvolatile metabolites separated the compounds by the TV and CV groups, as shown in the score plots (Figure 1). The distribution of the vinegar samples on the score plots suggested greater diversity in metabolites of the TVs than those of the CVs. The variable importance in projection (VIP) scores of the metabolites were positively correlated with the -Log ( $p$-value) for the volatile and nonvolatile compounds (Figure 1B,D); the correlation was stronger for the volatile compounds. This result suggests that the metabolomic differences between the TVs and CVs are better characterized by the volatile compounds. Although the comparison of TVs and CVs for their non-volatile and volatile compounds was conducted for the first time in this study, some recent studies have also pointed out that aroma profiles of vinegars are critically changed by different fermentation processes as well as raw materials $[9,19]$.

A total of 180 metabolites were identified from the TVs and CVs (Table 2, Supplementary Materials Table S1). Twenty of these metabolites were classified as being significantly different between the two groups (VIP scores $>1.0$, PLS-DA; $p<0.05, t$-test); among them, 18 metabolites were significantly more abundant in traditional vinegars, five of which were only detected in traditional vinegars (TV-only). On the other hand, two metabolites (ethyl 3-(methylthio)propionate and asparagine) were detected at significantly higher levels in commercial vinegars, and the former was only detected in commercial vinegars (CV-only). Eighteen out of 20 of the most significantly different metabolites were more abundant in the TV samples, suggesting that traditional vinegars were more enriched by both volatile and nonvolatile compounds.

Vinegar metabolites are enriched during fermentation and aging processes. Recently, it was found that the contents of some metabolites of vinegars such as lactic acid increased mostly during alcoholic fermentation [7]. In addition, aroma profiling of Chinese vinegars using GC/MS and GC-O suggested that volatile compounds are enriched during vinegar aging [10]. Similarly, an NMR-based metabolomic study reported that the concentrations of most vinegar metabolites increased after aging longer than a year [20]. Because TVs undergo alcoholic fermentation and require longer fermentation and aging periods, compounds that are significantly more abundant in TVs would be closely associated with fermentation processes. Meanwhile, in a prior study comparing non-volatile compounds of TVs and CVs, various sugars were significantly more abundant in CVs [18]. However, those sugars were not representative compounds of CVs in the present study due to large variations. 
Table 1. Vinegar samples used in this study.

\begin{tabular}{|c|c|c|c|c|c|}
\hline $\begin{array}{l}\text { Traditional } \\
\text { Vinegars }\left(^{*}\right)\end{array}$ & $\begin{array}{l}\text { Geographical Origin } \\
\text { in Korea }\end{array}$ & Raw Materials & Acetate $(g / L)$ & Ethanol $(\mathrm{g} / \mathrm{L})$ & $\begin{array}{l}\text { Glucose + } \\
\text { Fructose }(\mathrm{g} / \mathrm{L})\end{array}$ \\
\hline TV1 (101) & Yeongdong, Chungbuk & Persimmon & $37.6 \pm 0.2$ & $13.7 \pm 0.2$ & 0 \\
\hline TV2 (746) & Icheon, Gyeonggi & Persimmon & $62.4 \pm 1.6$ & $1.7 \pm 0.1$ & $0.3 \pm 0.03$ \\
\hline TV3 (163) & Jinju, Gyeongnam & Persimmon & $50.3 \pm 0.1$ & $2.5 \pm 0.1$ & 0 \\
\hline TV4 (553) & Wanju, Jeonbuk & Persimmon & $35.2 \pm 0.1$ & $13.1 \pm 0.3$ & 0 \\
\hline TV5 (135) & Jeongeup, Jeonbuk & Persimmon & $41.1 \pm 1.7$ & $12.7 \pm 0.7$ & $46.5 \pm 2.2$ \\
\hline TV6 (794) & Yeongcheon, Gyeongbuk & Brown rice & $42.8 \pm 1.5$ & $0.4 \pm 0.5$ & $30.7 \pm 1.1$ \\
\hline TV7 (378) & Yecheon, Gyeongbuk & Multigrains & $53.4 \pm 0.7$ & $4.6 \pm 0.1$ & $2.2 \pm 0.3$ \\
\hline $\begin{array}{l}\text { Commercial } \\
\text { Vinegars }\end{array}$ & Manufacturer & Raw Materials & Acetate $(g / L)$ & Ethanol $(\mathrm{g} / \mathrm{L})$ & $\begin{array}{l}\text { Glucose + } \\
\text { Fructose }(g / L)\end{array}$ \\
\hline CV1 & Ottogi & Apple & $64.5 \pm 2.0$ & $1.4 \pm 0.03$ & $11.3 \pm 0.4$ \\
\hline CV2 & Ottogi & plum & $63.5 \pm 1.2$ & $1.4 \pm 0.1$ & $4.1 \pm 0.01$ \\
\hline CV3 & Daesang & Apple & $51.6 \pm 0.4$ & $1.0 \pm 0.04$ & $8.8 \pm 0.1$ \\
\hline CV4 & Ottogi & Brown rice & $65.9 \pm 1.1$ & $1.5 \pm 0.1$ & $3.1 \pm 0.1$ \\
\hline
\end{tabular}

* Certification numbers (in parenthesis) issued by the Ministry of Agriculture, Food and Rural Affairs, Korea.

A

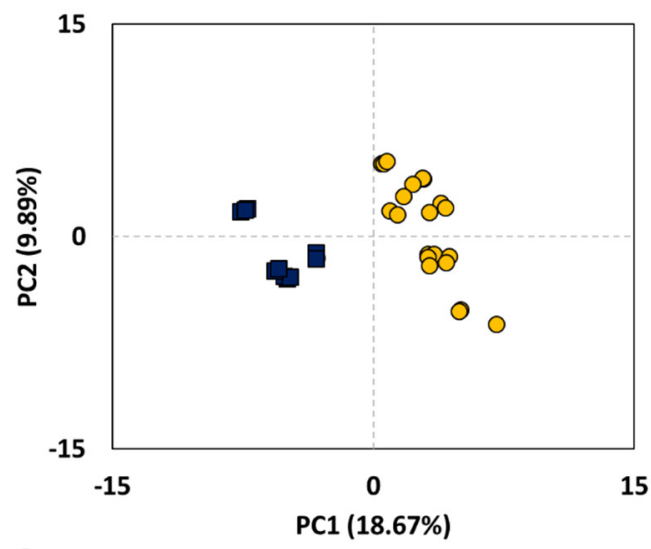

C

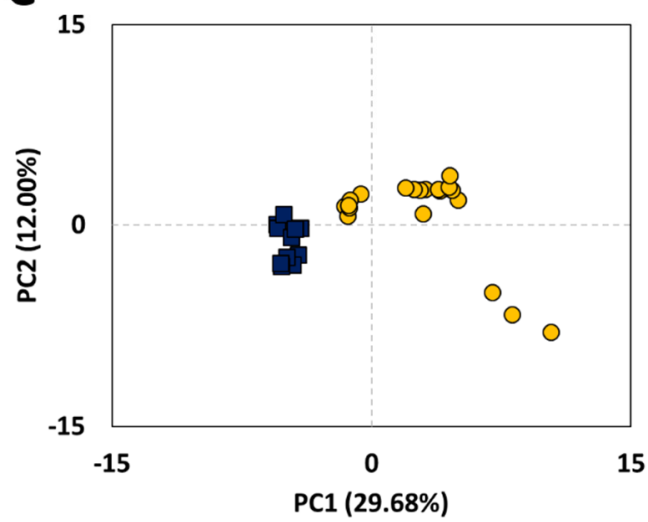

B

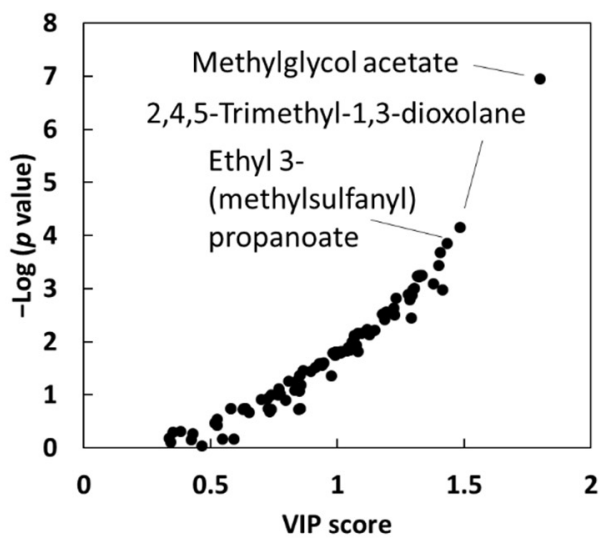

D

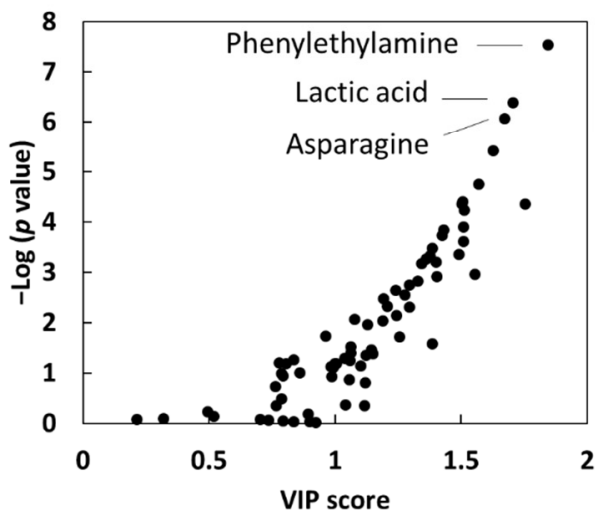

Figure 1. The partial least squares-discriminant analysis (PLS-DA) of the volatile (A,B) and nonvolatile (C,D) compounds of 11 vinegar samples (Table 1). (A,C) Score plots. (B,D) variable importance in projection (VIP) scores vs. -Log $p$-value plots of the 102 volatile (B) and 72 nonvolatile (D) compounds. 
Table 2. Number of vinegar metabolites identified.

\begin{tabular}{ccccc}
\hline & Total Metabolites & $\begin{array}{c}\text { Significantly Different } \\
\text { Metabolites * }\end{array}$ & $\begin{array}{c}\text { High in Traditional } \\
\text { Vinegars }{ }^{\mathbf{a}}\end{array}$ & $\begin{array}{c}\text { High in Commercial } \\
\text { Vinegars }\end{array}$ \\
\hline Volatile & 102 & 5 & $4(3)$ & $1(1)$ \\
Nonvolatile & 78 & 15 & $14(2)$ & $1(0)$ \\
Total & 180 & 20 & $18(5)$ & $2(1)$ \\
\hline
\end{tabular}

${ }^{*}$ VIP score $>1.0$ and $p$-value $<0.05 .{ }^{a}$ The numbers in parentheses refer to the number of TV-only compounds. ${ }^{\mathrm{b}}$ The numbers in parentheses refer to the number of CV-only compounds.

\subsection{TV-Only Compounds}

The five TV-only compounds only detected in traditional vinegars were 2,4,5-trimethyl1,3-dioxolane, 2-methoxyethyl acetate, phenylalanine ethyl ester, L-isoleucine, and phenylethylamine (VIP $>1.0$ and $p<0.05$ ) (Figure 2). Some of the compounds had wide interquartile and error ranges, suggesting that their contents varied greatly among different TV samples. Except for phenylalanine ethyl ester, four of the TV-only compounds were detected in all the traditional vinegar samples.

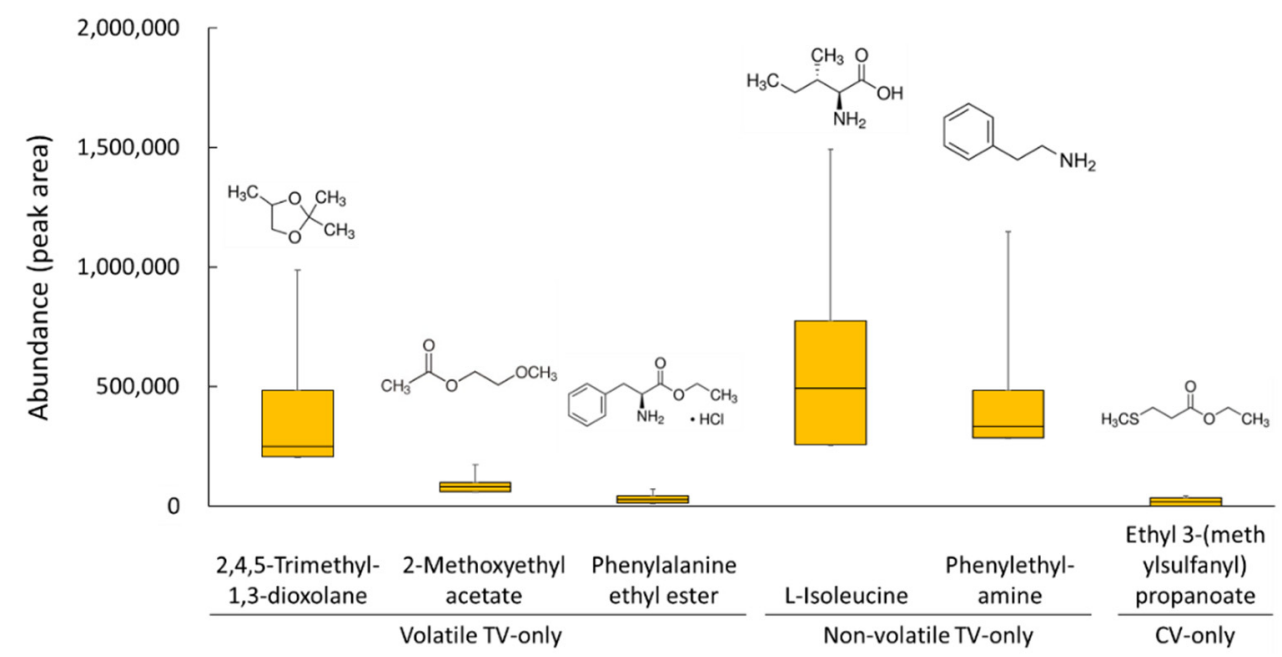

Figure 2. The abundance of six metabolites detected only in traditional vinegar (TV-only) or commercial vinegar (CV-only). The interquartile range (boxes), the largest and smallest values (error bars), and the medians (horizontal lines in the boxes) are indicated.

Three TV-only volatile compounds are unique metabolites associated with specific fermentation conditions. 2,4,5-Trimethyl-1,3-dioxolane was one of the compounds not found after fermentation but formed and accumulated during the aging process [10]. 2-Methoxyethyl acetate (acetic acid, methoxy-, ethyl ester) compounds are reported as flavor compounds of several ethnic foods, such as Korean soybean paste [21], Chinese liquor [22], and Burundian cassava flour [23]. Notably, 2-methoxyethyl acetate is detected only at the end of soybean fermentation; thus, it is associated with complex fermentation processes [21]. Phenylalanine ethyl ester (Phe-EE), one of the minor amino acid ethyl esters of wines, is formed during the second half of the fermentation when ethanol concentration is high $[24,25]$.

Surprisingly, common food metabolites like L-isoleucine, an amino acid, and phenylethylamine, an amino acid derivative, were identified as nonvolatile TV-only compounds. L-isoleucine is one of the amino acids found in most traditionally fermented vinegars [6]. L-isoleucine and other branched-chain amino acids are associated with the production of higher alcohols and esters during fermentation [26]. Phenylethylamine is one of the least common biogenic amines in wine and dairy products $[27,28]$. Previously, phenylethylamine was not detected in all the vinegars tested [17,29]. 
Meanwhile, there were 51 other TV-only compounds, 43 volatile and eight nonvolatile compounds, with a low significance $(p>0.05)$ due to sample variations, which were independent from raw materials (Supplementary Materials Table S2). Because some of those compounds are strongly related to fermentation, a selected group of TV-specific compounds might be useful as a potential marker for traditional vinegars. For example, 3phenyllactic acid $(p<0.085)$, one of the aromatic hydroxy acids that contributes to vinegar's flavor, is produced during fermentation using phenylalanine as a precursor, mainly by lactic acid bacteria [8].

\subsection{CV-Only Compounds}

Ethyl 3-(methylthio)propionate was the significant CV-only volatile compound detected from two commercial vinegar samples (VIP $>1.0$ and $p<0.05$ ) (Figure 2). Ethyl 3-(methylthio)propionate has recently been identified as a flavor-active compound in Chinese vinegar and Chinese liquor [9,30]. Previously, ethyl 3-methylthiopropionate was detected only when sugars or spices were added during vinegar fermentation [9]. This observation is consistent with our conclusion that it is specific to CVs containing various additives.

There were 19 other CV-only volatile compounds with a low significance $(p>0.05)$ due to sample variations (Table S2). The unique compounds of each sample might be associated with the different ingredients, such as brown rice, apple, and pineapple, of the CVs. For example, methyl 5-hexenoate, a unique volatile compound of pineapple [31], was detected only in CV2, a pineapple-based commercial vinegar. Notably, asparagine had the third-highest VIP score among the nonvolatile compounds due to its detection in all the CVs and only $1 \mathrm{TV}$.

\subsection{Common Vinegar Compounds}

Among the 20 compounds that were significantly different between TVs and CVs, four compounds (lactic acid, erythritol, propanoic acid, and 2,3-butanediol (denoted as its 2 TMS derivative, 3,6-dioxa-2,7-disilaoctane and hexamethyl, in some metabolomic studies)) were detected in all 11 vinegars tested; therefore, they were classified as common vinegar compounds (Figure 3). The four common vinegar compounds were nonvolatile and significantly high in TVs. Based on the median values of the common vinegar compounds, the relative abundance of lactic acid, 2,3-Butanediol, erythritol, and propionic acids were $71,29,9$, and 4 times higher in TVs than CVs, respectively.

Various indigenous microorganisms are present during the fermentation of TV [32], thus explaining the high levels of lactic acid, erythritol, propanoic acid, and 2,3-butanediol in TVs. Specifically, indigenous lactic acid bacteria are the dominant bacterial population during the alcoholic fermentation stage of TVs [33]. Heterofermentative metabolism of lactic acid bacteria leads to the accumulation of lactic acid and other minor compounds, including propanoic acid and 2,3-Butanediol [34]. Additionally, erythritol is a byproduct of nonSaccharomyces osmotolerant yeast, such as Candida magnoliae and Yarrowia lipolytica [35,36], which predominates in the initial stage of static acetic acid fermentation [14,32]. During acetic acid fermentation, ethanol concentration is reduced to $6 \%-7 \%$, allowing the growth of the non-Saccharomyces yeast such as C. magnoliae. Because most TVs are produced by static and slow acetic acid fermentation, the oxidation of erythritol to erythrulose by acetic acid bacteria may be limited [37], thus resulting in a high level of erythritol in TVs. 

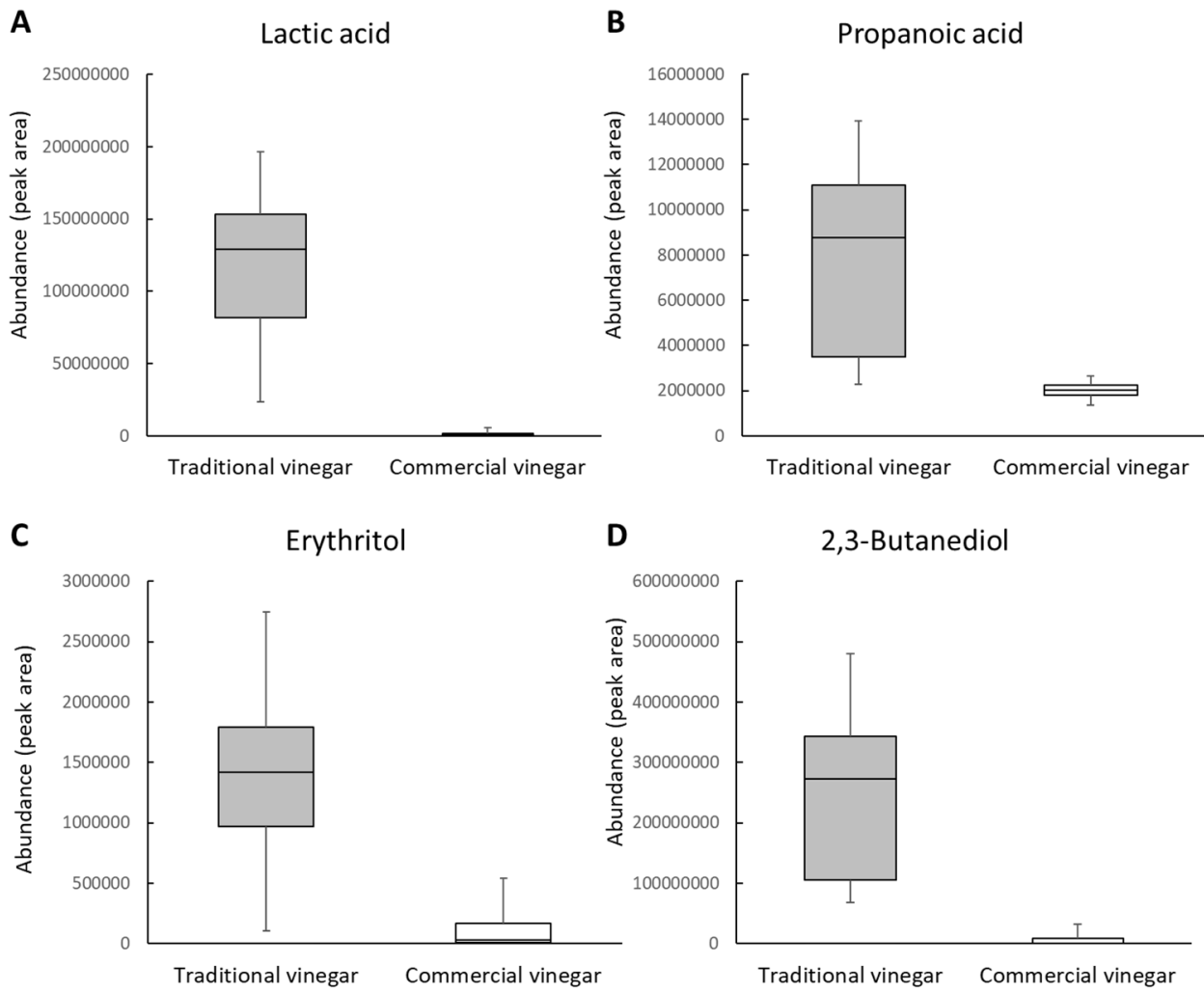

Figure 3. The comparison of the significantly more abundant compounds in TVs than those in CVs. Among the 20 significantly different compounds, lactic acid (A), propanoic acid (B), erythritol (C), and 2,3-butanediol (D) were detected in all vinegar samples. The interquartile range (boxes), largest and smallest values (error bars), and medians (horizontal lines in the boxes) are indicated for each compound.

\section{Materials and Methods}

\subsection{Raw Material Preparation}

All 7 traditional vinegars certified so far in Korea (the Ministry of Agriculture, Food and Rural Affairs, Korea) were purchased directly from each manufacturer, and four representative commercial vinegars were purchased from local markets in Korea (Table 1). Vinegars with various raw materials were selected to offset different metabolites originating from different raw materials.

\subsection{High-Performance Liquid Chromatography (HPLC) Analysis}

Acetate, ethanol, glucose, and fructose (Sigma-Aldrich, St. Louis, MO, USA) were quantitated using an HPLC (1260 series, Agilent Technologies, Santa Clara, CA, USA) system with an RI detector and a Rezex-ROA Organic Acid H+ (8\%, $150 \times 4.6 \mathrm{~mm})$ column (Phenomenex Inc., Torrance, CA, USA). The column was eluted with $0.005 \mathrm{~N} \mathrm{H}_{2} \mathrm{SO}_{4}$ (Sigma-Aldrich, St. Louis, MO, USA) at $0.6 \mathrm{~mL} / \mathrm{min}$ and $50{ }^{\circ} \mathrm{C}$. The dynamic range of the standard curves was $0.1-5 \mathrm{~g} / \mathrm{L}$, and samples were appropriately diluted prior to analysis. All samples were analyzed in triplicate.

\subsection{Sample Derivatization for Analysis}

Vinegar samples were derivatized with some modifications to previously reported methods [38]. For methoxyamination, $50 \mu \mathrm{L}$ of methoxyamine hydrochloride in $0.2 \%$ pyridine $(w / v)$ (Sigma-Aldrich, St. Louis, MO, USA) was added to $5 \mu \mathrm{L}$ of a dry-vacuumed vinegar sample. This mixture was then incubated for $90 \mathrm{~min}$ at $30{ }^{\circ} \mathrm{C}$. For trimethylsilylation, $50 \mu \mathrm{L}$ of N-methyl-N-(trimethylsilyl)trifluoroacetamide (Sigma-Aldrich) was added to the samples and incubated for $30 \mathrm{~min}$ at $37^{\circ} \mathrm{C}$. 


\subsection{Metabolite Analysis Using Gas Chromatography-Mass Spectrometry (GC/MS)}

For volatile compounds, $5 \mathrm{~mL}$ of samples were extracted by SPME fiber coated with dinylbenzene/carboxen/polydimethylsiloxane (Bellefonte, PA, USA) at $50{ }^{\circ} \mathrm{C}$ for $60 \mathrm{~min}$, as previously described [19]. The samples were injected by MPS autosampler (Gerstel, Muelheim, Germany) at a split mode (1:20) into the GC/MS system (7890-5977B; Agilent) equipped with a DB-WAS column $(60 \mathrm{~m} \times 0.25 \mathrm{~mm}, 0.25 \mu \mathrm{m}$ thickness; Agilent). The initial oven temperature was set to $40^{\circ} \mathrm{C}$ for $2 \mathrm{~min}$, ramped up by $20^{\circ} \mathrm{C} / \mathrm{min}$ until reaching the final temperature of $240{ }^{\circ} \mathrm{C}$, at which it was held for $5 \mathrm{~min}$. The mass selective spectra were operated in scan mode with a mass range of $500-550 \mathrm{~m} / \mathrm{z}$. All samples were analyzed in triplicate.

For nonvolatile compounds, $1-\mu \mathrm{L}$ aliquots of derivatized samples were injected in a split mode (1:50) into the gas chromatography-time-of-flight mass spectrometry (GC-TOF/MS) equipped with an Agilent 7890B GC, an RTX-5Sil MS column $(30 \mathrm{~m} \times 0.25 \mathrm{~mm}, 0.25-\mu \mathrm{m}$ in thickness; Restek, Bellefonte, PA, USA), an integrated guard column (10 m $\times 0.25 \mathrm{~mm}$, $0.25-\mu \mathrm{m}$ in thickness; Restek), and a Pegasus HT TOF MS (Leco, St. Joseph, MI, USA). The initial oven temperature was set to $75^{\circ} \mathrm{C}$ for $2 \mathrm{~min}$, ramped up by $15^{\circ} \mathrm{C} / \mathrm{min}$ until the final temperature of $300^{\circ} \mathrm{C}$, and held for $1.5 \mathrm{~min}$. The mass spectra of metabolites were obtained in the mass range of $45-500 \mathrm{~m} / \mathrm{z}$ at an acquisition rate of $17 \mathrm{spectra} / \mathrm{s}$. All samples were analyzed with six replicates. For laboratory quality control (QC), a blank and in-house QC mixture of alanine 2,3,3,3- $d_{4}$, glutamic-2,3,3,4,4-d $d_{5}$ acid, asparagine- $-{ }^{15} N_{2}-d_{8}$ and xylitol (Sigma-Aldrich, St. Louis, MO, USA) at a concentration of $0.08 \mathrm{mg}$ each were analyzed with each batch of analysis, and the coefficient of variation (CV) was kept below $10 \%$.

\subsection{Data Processing and Statistical Analysis}

For data processing, raw peak area values were used, as previously described $[8,18,39]$. For the quality assurance of the data, CVs for measured metabolites was calculated, and it was confirmed that the 10 metabolites with the highest abundance of each biological group had CVs less than $10 \%$. For identification of the metabolites, the raw data were processed by an automated mass spectral deconvolution and identification system (AMDIS) using the National Institute of Standard and Technology library (NIST 2014) with a similarity of more than $70 \%[40,41]$. The pre-processed data were further processed by SpectConnect (http:/ / spectconnect.mit.edu, accessed on 22 July 2021) [42] for peak alignment and for generating the data matrix. The statistical analysis was performed using partial least squares-discriminant analysis with STATISTICA (ver. 7.1; StatSoft, Tulsa, OK, USA) and MultiExperiment Viewer [43,44].

\section{Conclusions}

In this study, the metabolite profiles of TVs and CVs were analyzed and compared. A total of 180 volatile and nonvolatile compounds were identified, and TVs had a greater metabolite diversity than CVs. Twenty compounds significantly influenced the differentiation of TVs from CVs, which were classified into TV-only compounds, CV-only compounds, and common vinegar compounds. The compounds high in TVs were associated with complex microbial activities, while the compounds high in CVs were associated with commercial vinegar additives. The results provide comparative metabolite profiles of vinegars with different production processes. The selected compounds of vinegars can be applied as potential markers for vinegar fermentation processes as well as for authentic evaluation of vinegars in Korea.

Supplementary Materials: The following are available online at https:/ / www.mdpi.com/article/10 $.3390 /$ metabo11080478/s1, Table S1: Volatile and non-volatile metabolites detected in traditional and commercial vinegars, Table S2: Vinegar process-specific metabolites.

Author Contributions: Conceptualization, H.K., W.-C.K., M.-R.L. and S.-R.K.; methodology, J.-W.K., H.K. and W.-C.K.; software, J.-W.K., M.S. and S.K.; validation, M.S. and S.K.; formal analysis, J.-W.K. and B.G.; investigation, J.-W.K. and S.-R.K.; resources, H.K.; data curation, J.-W.K.; writing-original 
draft preparation, M.S.; writing-review and editing, M.S., M.-R.L. and S.-R.K.; visualization, M.S. and S.K.; supervision, M.-R.L. and S.-R.K.; project administration, M.-R.L. and S.-R.K.; funding acquisition, M.-R.L. and S.-R.K. All authors have read and agreed to the published version of the manuscript.

Funding: This research received no external funding.

Institutional Review Board Statement: Not applicable.

Informed Consent Statement: Not applicable.

Data Availability Statement: The data presented in this study are available in supplementary tables.

Conflicts of Interest: The authors declare no conflict of interest.

\section{References}

1. Verzelloni, E.; Tagliazucchi, D.; Conte, A. Relationship between the antioxidant properties and the phenolic and flavonoid content in traditional balsamic vinegar. Food Chem. 2007, 105, 564-571. [CrossRef]

2. Salbe, A.D.; Johnston, C.S.; Buyukbese, M.A.; Tsitouras, P.D.; Harman, S.M. Vinegar lacks antiglycemic action on enteral carbohydrate absorption in human subjects. Nutr. Res. 2009, 29, 846-849. [CrossRef]

3. Budak, N.H.; Kumbul Doguc, D.; Savas, C.M.; Seydim, A.C.; Kok Tas, T.; Ciris, M.I.; Guzel-Seydim, Z.B. Effects of apple cider vinegars produced with different techniques on blood lipids in high-cholesterol-fed rats. J. Agric. Food Chem. 2011, 59, 6638-6644. [CrossRef]

4. Petsiou, E.I.; Mitrou, P.I.; Raptis, S.A.; Dimitriadis, G.D. Effect and mechanisms of action of vinegar on glucose metabolism, lipid profile, and body weight. Nutr. Rev. 2014, 72, 651-661. [CrossRef]

5. Pazuch, C.M.; Siepmann, F.B.; Canan, C.; Colla, E. Vinegar: Functional aspects. Científica 2015, 43, 302-308. [CrossRef]

6. Xia, T.; Zhang, B.; Duan, W.; Zhang, J.; Wang, M. Nutrients and bioactive components from vinegar: A fermented and functional food. J. Funct. Foods 2020, 64, 103681. [CrossRef]

7. Kim, E.-J.; Cho, K.-M.; Kwon, S.J.; Seo, S.-H.; Park, S.-E.; Son, H.-S. Factors affecting vinegar metabolites during two-stage fermentation through metabolomics study. LWT 2021, 135, 110081. [CrossRef]

8. Zhao, G.; Kuang, G.; Li, J.; Hadiatullah, H.; Chen, Z.; Wang, X.; Yao, Y.; Pan, Z.-H.; Wang, Y. Characterization of aldehydes and hydroxy acids as the main contribution to the traditional Chinese rose vinegar by flavor and taste analyses. Food Res. Int. 2020, 129, 108879. [CrossRef]

9. Al-Dalali, S.; Zheng, F.; Sun, B.; Zhou, C.; Li, M.; Chen, F. Effects of different brewing processes on the volatile flavor profiles of Chinese vinegar determined by HS-SPME-AEDA with GC-MS and GC-O. LWT 2020, 133, 109969. [CrossRef]

10. Al-Dalali, S.; Zheng, F.; Sun, B.; Chen, F. Comparison of Aroma Profiles of Traditional and Modern Zhenjiang Aromatic Vinegars and Their Changes During the Vinegar Aging by SPME-GC-MS and GC-O. Food Anal. Methods 2019, 12, 544-557. [CrossRef]

11. Pinu, F.R.; de Carvalho-Silva, S.; Trovatti Uetanabaro, A.P.; Villas-Boas, S.G. Vinegar Metabolomics: An Explorative Study of Commercial Balsamic Vinegars Using Gas Chromatography-Mass Spectrometry. Metabolites 2016, 6, 22. [CrossRef] [PubMed]

12. Ishihara, S.; Inaoka, T.; Nakamura, T.; Kimura, K.; Sekiyama, Y.; Tomita, S. Nuclear magnetic resonance- and gas chromatography/mass spectrometry-based metabolomic characterization of water-soluble and volatile compound profiles in cabbage vinegar. J. Biosci. Bioeng. 2018, 126, 53-62. [CrossRef]

13. Chen, H.; Chen, T.; Giudici, P.; Chen, F. Vinegar functions on health: Constituents, sources, and formation mechanisms. Compr. Rev. Food Sci. Food Saf. 2016, 15, 1124-1138. [CrossRef]

14. Li, S.; Li, P.; Feng, F.; Luo, L.-X. Microbial diversity and their roles in the vinegar fermentation process. Appl. Microbiol. Biotechnol. 2015, 99, 4997-5024. [CrossRef]

15. Yetiman, A.E.; Kesmen, Z. Identification of acetic acid bacteria in traditionally produced vinegar and mother of vinegar by using different molecular techniques. Int. J. Food Microbiol. 2015, 204, 9-16. [CrossRef] [PubMed]

16. Ning, Z.; Liu, Z.; Song, Z.; Wang, C.; Liu, Y.; Gan, J.; Ma, X.; Lu, A. Application of a strategy based on metabolomics guided promoting blood circulation bioactivity compounds screening of vinegar. Chem. Cent. J. 2017, 11, 1-12. [CrossRef]

17. Ordóñez, J.L.; Callejón, R.M.; Morales, M.L.; García-Parrilla, M.C. A survey of biogenic amines in vinegars. Food Chem. 2013, 141, 2713-2719. [CrossRef] [PubMed]

18. Jang, Y.K.; Lee, M.Y.; Kim, H.Y.; Lee, S.; Yeo, S.H.; Baek, S.Y.; Lee, C.H. Comparison of traditional and commercial vinegars based on metabolite profiling and antioxidant activity. J. Microbiol. Biotechnol. 2015, 25, 217-226. [CrossRef]

19. Kim, J.W.; Jeong, D.; Lee, Y.; Hahn, D.; Nam, J.O.; Lee, W.Y.; Hong, D.H.; Kim, S.R.; Ha, Y.S. Development and Metabolite Profiling of Elephant Garlic Vinegar. J. Microbiol. Biotechnol. 2018, 28, 50-58. [CrossRef]

20. Nie, J.; Li, Y.; Xing, J.; Chao, J.; Qin, X.; Li, Z. Comparison of two types of vinegar with different aging times by NMR-based metabolomic approach. J. Food Biochem. 2019, 43, e12835. [CrossRef] [PubMed]

21. Cho, K.M.; Lim, H.-J.; Kim, M.-S.; Kim, D.S.; Hwang, C.E.; Nam, S.H.; Joo, O.S.; Lee, B.W.; Kim, J.K.; Shin, E.-C. Time course effects of fermentation on fatty acid and volatile compound profiles of Cheonggukjang using new soybean cultivars. J. Food Drug Anal. 2017, 25, 637-653. [CrossRef] 
22. Zhu, S.; Lu, X.; Ji, K.; Guo, K.; Li, Y.; Wu, C.; Xu, G. Characterization of flavor compounds in Chinese liquor Moutai by comprehensive two-dimensional gas chromatography/time-of-flight mass spectrometry. Anal. Chim. Acta 2007, 597, 340-348. [CrossRef]

23. Aloys, N. Volatile compounds in Ikivunde and Inyange, two Burundian cassava products. Glob. Adv. Res. J. Food Sci. Technol. 2012, 1, 1-7.

24. Herraiz, T.; Ough, C.S. Identification and determination of amino acid ethyl esters in wines by capillary gas chromatography-mass spectrometry. J. Agric. Food Chem. 1992, 40, 1015-1021. [CrossRef]

25. Herraiz, T.; Ough, C.S. Formation of Ethyl Esters of Amino Acids by Yeasts during the Alcoholic Fermentation of Grape Juice. Am. J. Enol. Vitic. 1993, 44, 41-48.

26. Ferreira, I.M.; Guido, L.F. Impact of Wort Amino Acids on Beer Flavour: A Review. Fermentation 2018, 4, 23. [CrossRef]

27. Spano, G.; Russo, P.; Lonvaud-Funel, A.; Lucas, P.; Alexandre, H.; Grandvalet, C.; Coton, E.; Coton, M.; Barnavon, L.; Bach, B.; et al. Biogenic amines in fermented foods. Eur. J. Clin. Nutr. 2010, 64, S95-S100. [CrossRef] [PubMed]

28. Jia, S.; Kang, Y.P.; Park, J.H.; Lee, J.; Kwon, S.W. Determination of biogenic amines in Bokbunja (Rubus coreanus Miq.) wines using a novel ultra-performance liquid chromatography coupled with quadrupole-time of flight mass spectrometry. Food Chem. 2012, 132, 1185-1190. [CrossRef]

29. Song, N.-E.; Cho, H.-S.; Baik, S.-H. Bacteria isolated from Korean black raspberry vinegar with low biogenic amine production in wine. Braz. J. Microbiol. 2016, 47, 452-460. [CrossRef] [PubMed]

30. Sun, J.; Li, Q.; Luo, S.; Zhang, J.; Huang, M.; Chen, F.; Zheng, F.; Sun, X.; Li, H. Characterization of key aroma compounds in Meilanchun sesame flavor style baijiu by application of aroma extract dilution analysis, quantitative measurements, aroma recombination, and omission/addition experiments. RSC Adv. 2018, 8, 23757-23767. [CrossRef]

31. Montero-Calderón, M.; Rojas-Graü, M.A.; Martín-Belloso, O. Aroma Profile and Volatiles Odor Activity along Gold Cultivar Pineapple Flesh. J. Food Sci. 2010, 75, S506-S512. [CrossRef]

32. Song, N.-E.; Jeong, D.-Y.; Baik, S.-H. Application of indigenous Saccharomyces cerevisiae to improve the black raspberry (Rubus coreanus Miquel) vinegar fermentation process and its microbiological and physicochemical analysis. Food Sci. Biotechnol. 2018, 28, 481-489. [CrossRef]

33. Wu, J.J.; Ma, Y.K.; Zhang, F.F.; Chen, F.S. Biodiversity of yeasts, lactic acid bacteria and acetic acid bacteria in the fermentation of "Shanxi aged vinegar", a traditional Chinese vinegar. Food Microbiol. 2012, 30, 289-297. [CrossRef]

34. Rather, I.A.; Bajpai, V.K.; Huh, Y.S.; Han, Y.-K.; Bhat, E.A.; Lim, J.; Paek, W.K.; Park, Y.-H. Probiotic Lactobacillus sakei proBio-65 Extract Ameliorates the Severity of Imiquimod Induced Psoriasis-Like Skin Inflammation in a Mouse Model. Front. Microbiol. 2018, 9. [CrossRef] [PubMed]

35. Carly, F.; Fickers, P. Erythritol production by yeasts: A snapshot of current knowledge. Yeast 2018, 35, 455-463. [CrossRef]

36. Ye, S.; Park, H.; Kwak, Y.; Jeong, D.; Kim, S.R. Isolation of a New Yeast Strain Producing Erythritol. KSBB J. 2019, 34, 25-30. [CrossRef]

37. Mamlouk, D.; Gullo, M. Acetic Acid bacteria: Physiology and carbon sources oxidation. Indian J. Microbiol. 2013, 53, 377-384. [CrossRef] [PubMed]

38. Shin, M.; Kim, S.R. Metabolic Changes Induced by Deletion of Transcriptional Regulator GCR2 in Xylose-Fermenting Saccharomyces cerevisiae. Microorganisms 2020, 8, 1499. [CrossRef]

39. Chung, N.; Jo, Y.; Joe, M.-H.; Jeong, M.-H.; Jeong, Y.-J.; Kwon, J.-H. Rice vinegars of different origins: Discriminative characteristics based on solid-phase microextraction and gas chromatography with mass spectrometry, an electronic nose, electronic tongue and sensory evaluation. J. Inst. Brew. 2017, 123, 159-166. [CrossRef]

40. Cho, S.W.; Ko, H.J.; Park, T.H. Identification of a Lung Cancer Biomarker Using a Cancer Cell Line and Screening of Olfactory Receptors for Biomarker Detection. Biotechnol. Bioprocess Eng. 2021, 26, 55-62. [CrossRef]

41. Yun, E.J.; Oh, E.J.; Liu, J.-J.; Yu, S.; Kim, D.H.; Kwak, S.; Kim, K.H.; Jin, Y.-S. Promiscuous activities of heterologous enzymes lead to unintended metabolic rerouting in Saccharomyces cerevisiae engineered to assimilate various sugars from renewable biomass. Biotechnol. Biofuels 2018, 11, 140. [CrossRef] [PubMed]

42. Styczynski, M.P.; Moxley, J.F.; Tong, L.V.; Walther, J.L.; Jensen, K.L.; Stephanopoulos, G.N. Systematic Identification of Conserved Metabolites in GC/MS Data for Metabolomics and Biomarker Discovery. Anal. Chem. 2007, 79, 966-973. [CrossRef] [PubMed]

43. Saeed, A.I.; Bhagabati, N.K.; Braisted, J.C.; Liang, W.; Sharov, V.; Howe, E.A.; Li, J.; Thiagarajan, M.; White, J.A.; Quackenbush, J. TM4 Microarray Software Suite. Methods Enzymol. 2006, 411, 134-193. [CrossRef] [PubMed]

44. Denkert, C.; Budczies, J.; Weichert, W.; Wohlgemuth, G.; Scholz, M.; Kind, T.; Niesporek, S.; Noske, A.; Buckendahl, A.; Dietel, M.; et al. Metabolite profiling of human colon carcinoma-Deregulation of TCA cycle and amino acid turnover. Mol. Cancer 2008, 7, 72. [CrossRef] 